\title{
Article \\ Thermal Performance of Lithium Titanate Oxide Anode Based Battery Module under High Discharge Rates
}

\author{
Zehui Liu ${ }^{1,2}{ }^{\circ}$, Yinghui Gao ${ }^{1,3, *}$, Hongtao Chen ${ }^{1}$, Chu Wang ${ }^{1,2}$, Yaohong Sun ${ }^{1,2, *}$ and Ping Yan ${ }^{2,4}$ \\ 1 Institute of Electrical Engineering, Chinese Academy of Sciences, Beijing 100190, China; \\ liuzehui_cc@163.com (Z.L.); chenhongtao@mail.iee.ac.cn (H.C.); wangchu@mail.iee.ac.cn (C.W.) \\ 2 School of Electronic, Electrical and Communication Engineering, University of Chinese Academy of Sciences, \\ Beijing 100049, China; pingyan@mail.iee.ac.cn \\ 3 Institute of Electrical Engineering and Advanced Electromagnetic Drive Technology, Qilu Zhongke, \\ Jinan 250013, China \\ 4 Key Laboratory of Power Electronics and Electric Drive, Institute of Electrical Engineering, \\ Chinese Academy of Sciences, Beijing 100190, China \\ * Correspondence: gyh@mail.iee.ac.cn (Y.G.); yhsun@mail.iee.ac.cn (Y.S.)
}

check for updates

Citation: Liu, Z.; Gao, Y.; Chen, H.; Wang, C.; Sun, Y.; Yan, P. Thermal Performance of Lithium Titanate Oxide Anode Based Battery Module under High Discharge Rates. World Electr. Veh. J. 2021, 12, 158. https:// doi.org/10.3390/wevj12030158

Academic Editors: C. C. Chan, Yoichi Hori, James L. Kirtley, Jr., Joeri Van Mierlo, Myoungho Sunwoo and Xuhui Wen

Received: 17 August 2021

Accepted: 9 September 2021

Published: 20 September 2021

Publisher's Note: MDPI stays neutral with regard to jurisdictional claims in published maps and institutional affiliations.

Copyright: (c) 2021 by the authors. Licensee MDPI, Basel, Switzerland. This article is an open access article distributed under the terms and conditions of the Creative Commons Attribution (CC BY) license (https:// creativecommons.org/licenses/by/ $4.0 /)$.

\begin{abstract}
A lithium titanate oxide (LTO) anode based battery has high power density, and it is widely applied in transportation and energy storage systems. However, the thermal performance of LTO anode based battery module is seldom studied. In this work, a heat generation theoretical model of the battery is explored. The thermal performance of LTO anode based battery modules under high discharge rates is studied by both experiment and simulation. It is found that the temperature rise of the battery can be estimated accurately with the calculation of the equivalent internal resistance under different discharge rates. In addition, under the same depth of discharge, both the temperature rise and the temperature difference in the battery module increase with the discharge rates.
\end{abstract}

Keywords: thermal performance; LTO battery module; HPPC; high discharge rates

\section{Introduction}

A lithium-ion battery (LIB) is an important form of chemical power source, with high specific energy, long cycle life, wide operating temperature range, and flexible mobility [1-6]. It can provide high power output through the series and parallel connection of lithium-ion batteries, which is suitable for application in different scenarios. In addition, as sustainable energy, lithium-ion batteries are environmentally friendly.

As a chemical power source, the performance of lithium-ion batteries is affected by temperature. At low temperatures, the electrical performance of lithium batteries is suppressed, a large amount of heat is generated locally, and electrical energy is dissipated in the form of thermal energy; at high temperatures, thermal failure problems are prone to occur, which leads to problems such as smoke, fire, and explosion. In addition, temperature inconsistencies will increase battery inconsistencies. Therefore, battery thermal management technology is needed to ensure that the lithium-ion battery works at an appropriate temperature, while minimizing the temperature difference of the lithium battery in the module [7].

The current research of thermal management technology includes two aspects: one is the study of heat generation characteristics [8-12]; the other is the study of heat dissipation characteristics [13-16]. For the study of heat generation characteristics, Hosseinzadeh et al. [17] used an electrochemical-thermal model to predict the thermal performance in $5 \mathrm{C}$ discharge; Peng et al. [11] optimized the active air-cooling system by optimizing the battery arrangement after testing the calorific value and heat generation rate of each battery cell. However, the methods of the electrochemical-thermal model and testing the calorific method are both complicated; they are not suitable for the calculation with a large number of battery cells. 
In addition, for both heat generation and heat dissipation, the research mostly concerns the battery cells under discharge rates smaller than $5 \mathrm{C}$.

For the discharge over $5 \mathrm{C}$, it is well believed the heat generation can be estimated by ohmic Joule heat [18], which is equal to ${ }^{2} \mathrm{Rt}$ [12]. The commonly used resistance measurement methods include the hybrid pulse power characteristic (HPPC) method [19-21], the electrochemical impedance spectroscopy (EIS) method [22,23], the voltmeter-ammeter (V-I) method [24], etc. Among the methods, the HPPC and V-I methods are dynamic measurement methods, and they are more accurate for actual working conditions. However, the standard of timescale in the HPPC and V-I has not been unified. In the previous research of our group, we found that the ohmic Joule heat cannot substitute for the whole heat generation, and then we proposed a fast heat generation estimation method for an LTO anode based battery [25]. It is found that heat generation under a higher discharge rate can be estimated using the HPPC with a shorter time scale. The calculation of the internal resistance used the same time scale as in [25] because of using the same battery type.

In this paper, the heat generation characteristics are studied based on the LTO anode based battery module. The heat generation estimation method is testified through both simulation and experiment.

\section{Testing Object}

Two commercial LTO anode based battery modules were tested in the experiment. Each battery module consists of 20 Ah LTO anode based batteries (GCCLTT90 made by GCC Corp, Sichuan, China). The nominal voltage of the battery module was $24 \mathrm{~V}$, and it could achieve a maximum discharge current for $400 \mathrm{~A}$. The battery module used in this experiment contains 11 battery cells connected in series, as shown in Figure 1. A passive air cooling strategy without fins was used to dissipate the heat. The battery module was charged and discharged by using charge and discharge test equipment (CE-7001-100V500A made by Neware Corp, Shenzhen, China). The precision of the discharge equipment was $\pm 0.1 \%$ of FS. The temperature distribution was recorded by using a thermal infrared imager (Fluke Tix580 made by Fluke Corp, Washington, DC, USA). The temperature measurement range of the device was set to the range of -20 to $80^{\circ} \mathrm{C}$, and the temperature measurement accuracy was $2{ }^{\circ} \mathrm{C}$. The average temperature rise during the discharge was calculated by the average temperature at each pixel of thermal infrared imaging on the module.

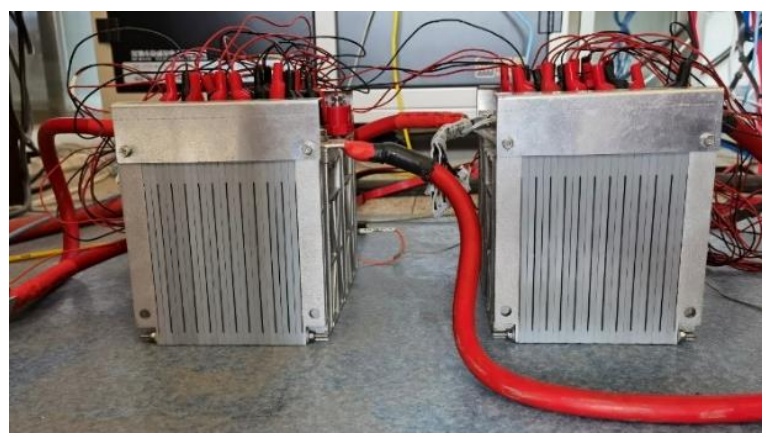

(a)

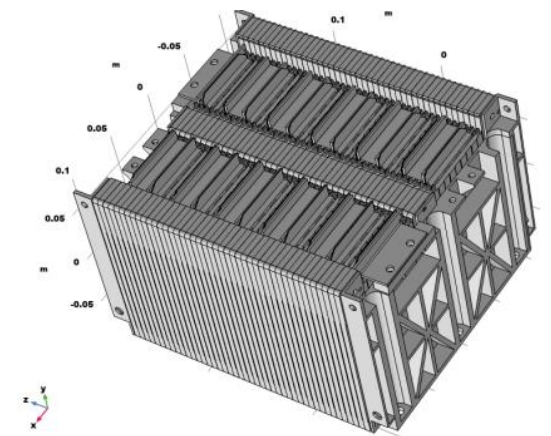

(b)

Figure 1. Schematic of the battery modules: (a) object pictures; (b) engineering drawing.

\section{Test Results}

\subsection{Test Results of Modules in Series}

The modules were discharged under the constant current profile of $200 \mathrm{~A}$ for $3 \mathrm{~min}$, which was a $50 \%$ depth of discharge (DOD). The module under the discharge can work within an appropriate temperature range. The temperature rises during the discharge process were compared. In the experiment, the room temperature was kept to $20 \pm 2{ }^{\circ} \mathrm{C}$. The detailed test process is that the modules were fully charged under a constant current and constant voltage $(\mathrm{CCCV})$ charging mode, firstly at a charging rate of $1 \mathrm{C}$, and then 
the module rested for $2 \mathrm{~h}$; after that, the module was discharged under $200 \mathrm{~A}$. To prevent complex wiring, the modules were tested one by one.

The test results of the modules in series are shown in Figure 2. The batteries in the two modules are highly consistent; therefore, the tendency of average temperature rise is similar. The maximum temperature point appears randomly due to the little difference in the internal resistance in the batteries. The average temperature rise of module $\mathrm{A}$ is about $6.7^{\circ} \mathrm{C}$, which is from 21.7 to $28.4^{\circ} \mathrm{C}$, while the average temperature rise of module $\mathrm{B}$ is about $8.1{ }^{\circ} \mathrm{C}$, which is from 17.8 to $25.9^{\circ} \mathrm{C}$. When the currents going through the two modules are the same, the heat generation is proportional to the internal resistance. It is inferred that the internal resistance of module B is higher than that of module A. The final temperature of module $\mathrm{A}$ is higher than module $\mathrm{B}$ with a smaller temperature rise, which is because the initial temperature of module $A$ is higher than module $B$.

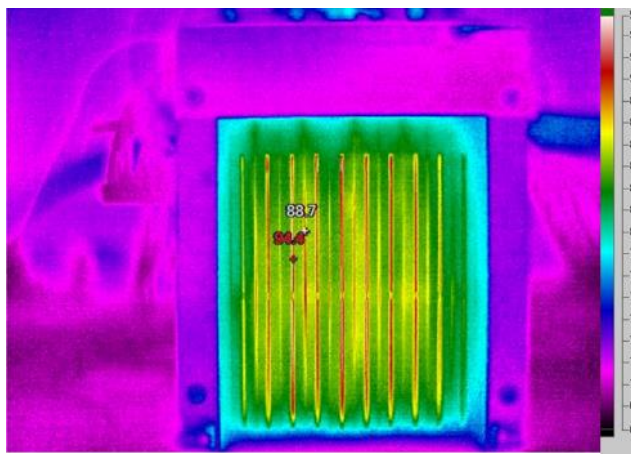

(a)

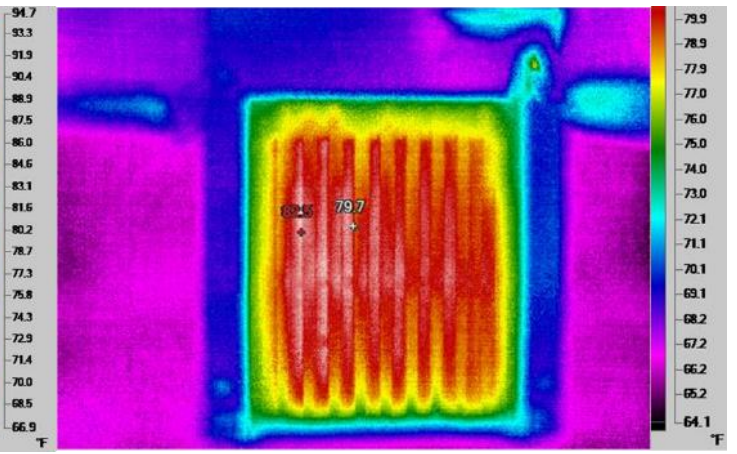

(b)

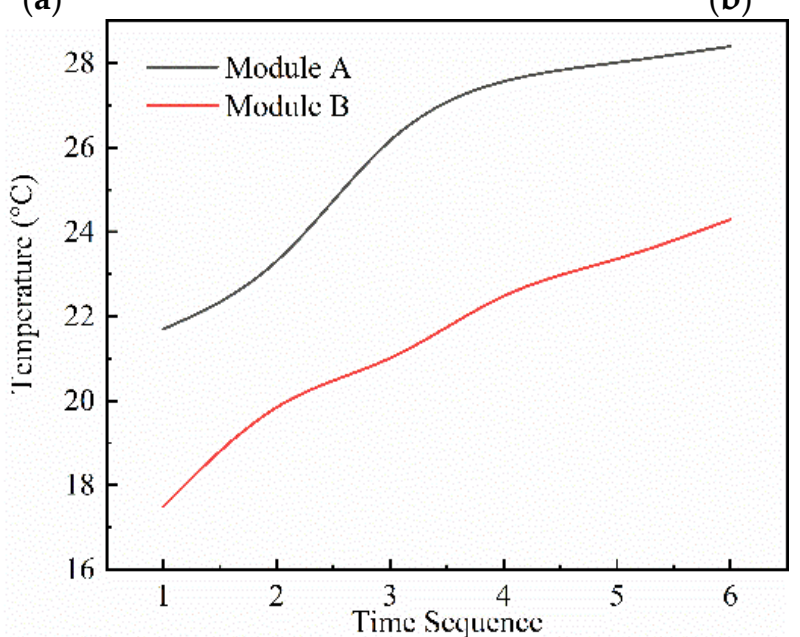

(c)

Figure 2. Test results of the modules under 200 A discharge: (a) temperature distribution of module $\mathrm{A} ;(\mathbf{b})$ temperature distribution of module $\mathrm{B}$; (c) variation of average temperature of module $\mathrm{A}$ and module B with the discharge.

\subsection{Test Results of Modules in Parallel}

The test results of the modules in parallel are shown in Figure 3. The whole current was $400 \mathrm{~A}$, the discharge time was also $3 \mathrm{~min}$, and the module with the smaller internal resistance went through a larger current. The average temperature rise of module $\mathrm{A}$ is about $6.8^{\circ} \mathrm{C}$, while the average temperature rise of module B is about $5.4^{\circ} \mathrm{C}$, which is different from the test results of the modules in series. The heat generated in the battery is proportional to the square of the current based on the Bernadi's equation and the fast heat generated estimation method $[12,25]$. Therefore, little internal resistance leads to a large temperature difference. The test results of the modules in parallel also infers that the 
internal resistance of module B is higher than that of module A. Additionally, the value of the internal resistance of each module will be quantified in the next part.

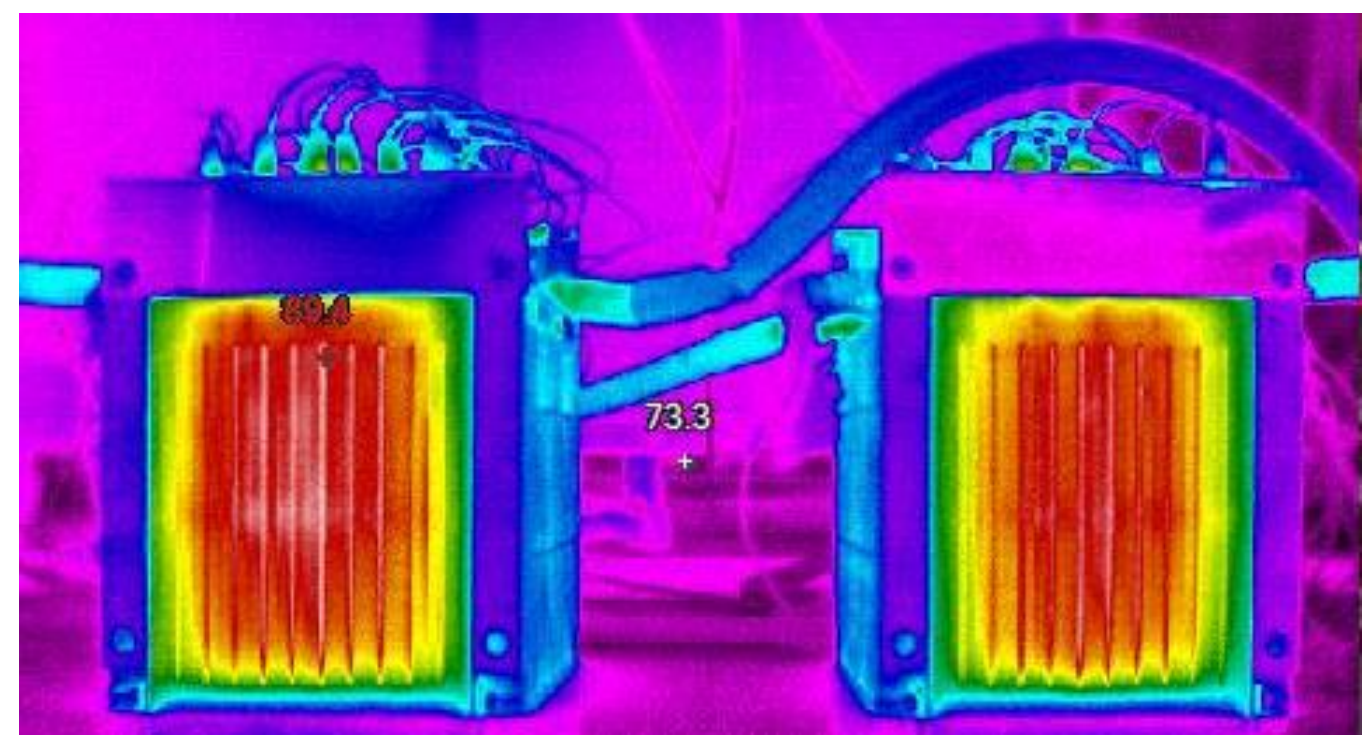

Figure 3. Test results of the modules in parallel.

\section{Discussion}

\subsection{Influence of Internal Resistance on Battery Thermal Characteristics}

The HPPC test is a precise method to measure the internal resistance of the batteries. The test procedure of HPPC was as follows: (1) the battery was charged to a full charge state at a $1 \mathrm{C}$ rate; (2) stood for $1 \mathrm{~h}$; (3) the battery was discharged at a preset discharge rate for $10 \mathrm{~s}$; (4) stood for $40 \mathrm{~s}$; (5) the battery was discharged at $1 \mathrm{C}$ rate to the next $10 \% \mathrm{SOC}$; (6) stood for $1 \mathrm{~h}$; (7) the procedure from step three to step six was repeated. The internal resistance is the voltage drop within $4 \mathrm{~s}$ divided by the current. In the experiment, the modules were discharged from a $100 \%$ SOC to a $50 \%$ SOC, thus the HPPC test corresponds to the discharge process. Additionally, for the internal resistance, the battery was fitted using the backward interpolation method; the test results of internal resistance are from $100 \%$ to $60 \%$.

The internal resistance is distributed around the electrical attach between the batteries and into the batteries. The electrical attaches adopt the same ultrasonic bonding technique, and they could be seen as the same resistance value. The batteries are the main heat source; the resistance we obtained is evenly distributed on each battery without considering the inconsistency of the battery. The results of the internal resistance of batteries in module A and B are shown in Figure 4. The maximum internal resistance appears at a 100\% SOC, and with the decrease in the SOC, the internal resistance is decreasing. The average internal resistance in module $\mathrm{A}$ is $1.12 \mathrm{~m} \Omega$, and the average internal resistance in module $\mathrm{B}$ is $1.13 \mathrm{~m} \Omega$.

\subsection{Simulation}

The model was simplified for the simulation. The body of the battery, the foams between the batteries, and the battery frameworks were kept, as shown in Figure 5. The parameters we set are shown in Table 1. The internal resistances obtained in Section 4.1 were used in the simulation, and the final results are shown in Figure 6. The simulation fits for the continuity equation, the momentum equation, and the energy equation. The boundary condition is shown in the following Equation (1):

$$
I^{2} R \mathrm{t}=\mathrm{q}_{b a t t}=m c \frac{d T}{d t}+h\left(T-T_{a m b}\right)+k\left(u_{x x}+u_{y y}+u_{z z}\right)
$$


In which, $\mathrm{q}_{\text {batt }}$ is the heat generation of the battery; $I$ is the current going through the battery; $R$ is the average internal resistance of the battery; $t$ is the discharge time; $m$ is the weight of the battery; $c$ is the heat capacity of the battery; $T$ is the real-time temperature; $T_{a m b}$ is the room temperature; $h$ is the thermal convection coefficient, and it is set to 10 in the simulation; $k$ is the heat conductivity coefficient; and $u_{x x}, u_{y y}$, and $u_{z z}$ are the second derivative of temperature with respect to the three spatial axes, respectively.

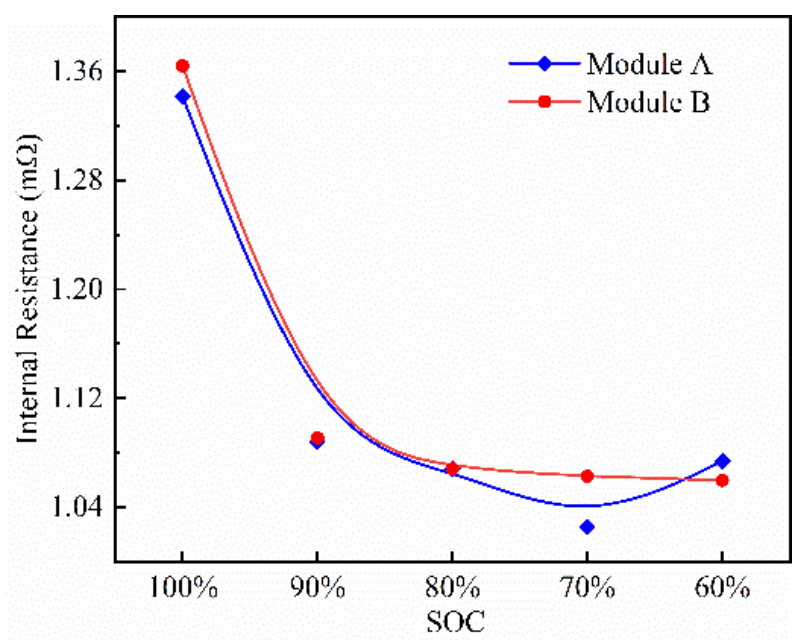

Figure 4. Results of the internal resistance of batteries in module A and B.

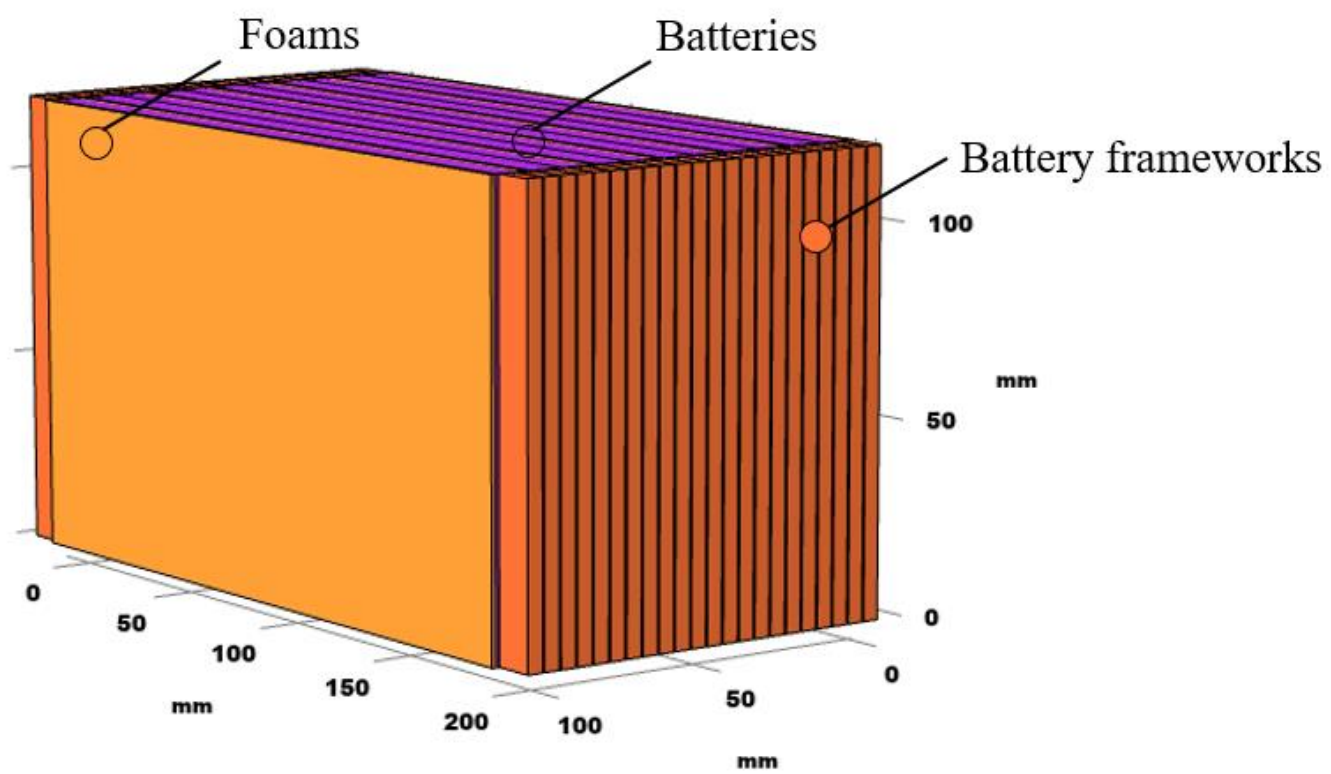

Figure 5. The schematic of the simulation.

Table 1. The parameters set in the simulation.

\begin{tabular}{cccc}
\hline & Density $/\left(\mathbf{k g} / \mathbf{m}^{\mathbf{3}}\right)$ & Thermal Conductivity/(W/(m·K)) & Specific Heat/(J/(kg.K)) \\
\hline batteries & 2193 & $2.5,14.5,14.5$ & 1142 \\
foams & 50 & 0.12 & 2050 \\
frameworks & 962 & 0.42 & 2300 \\
\hline
\end{tabular}




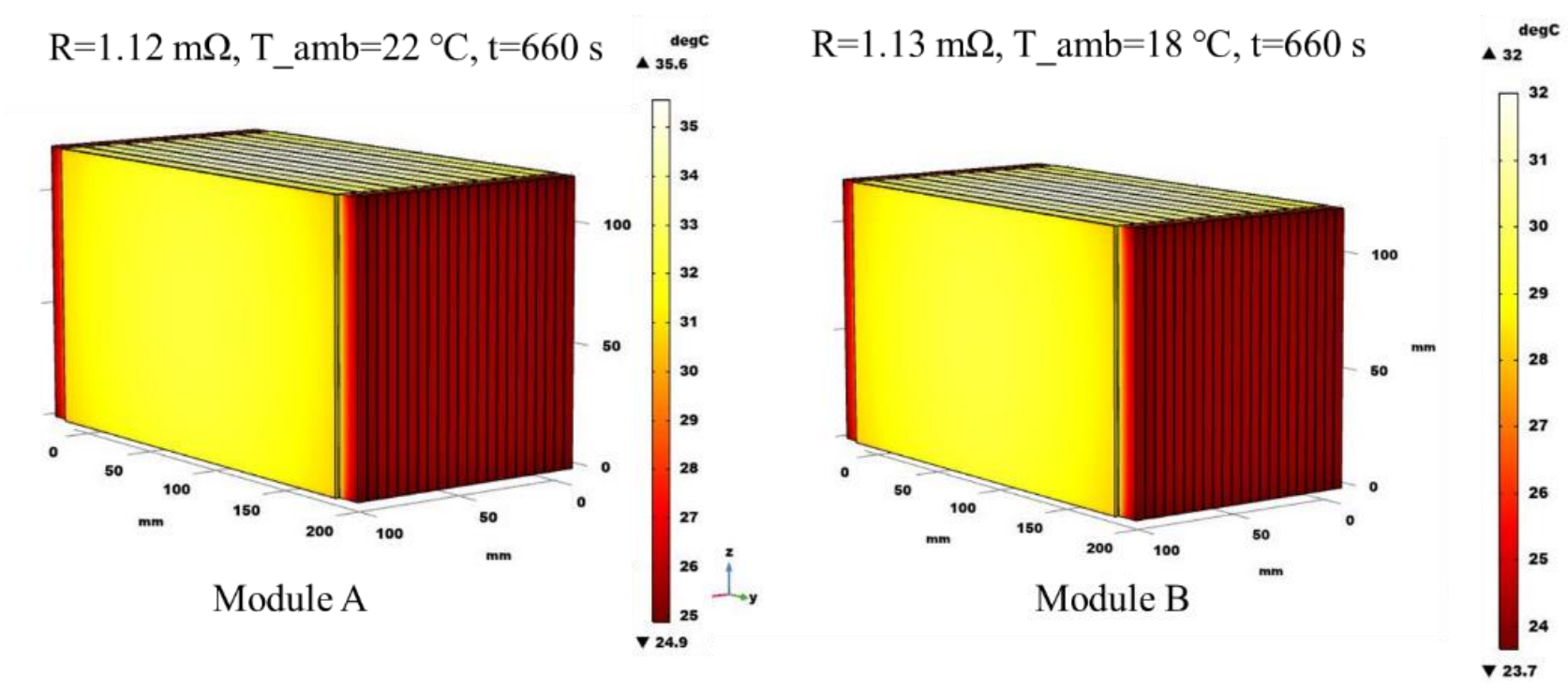

(a)

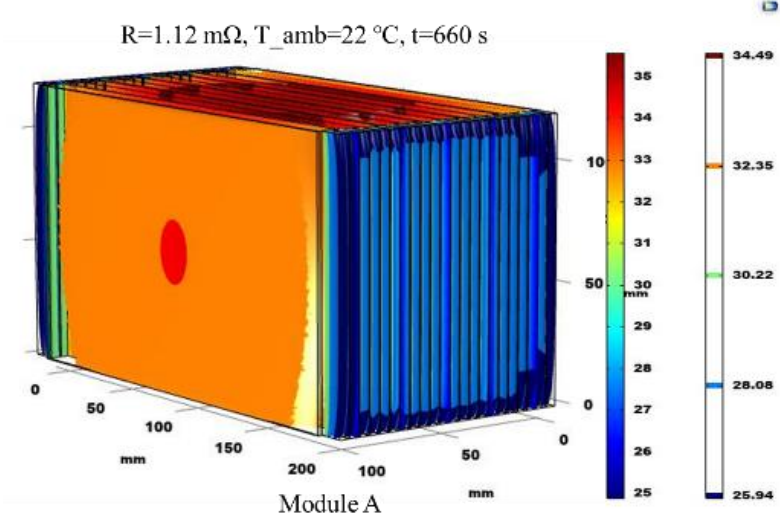

(c)

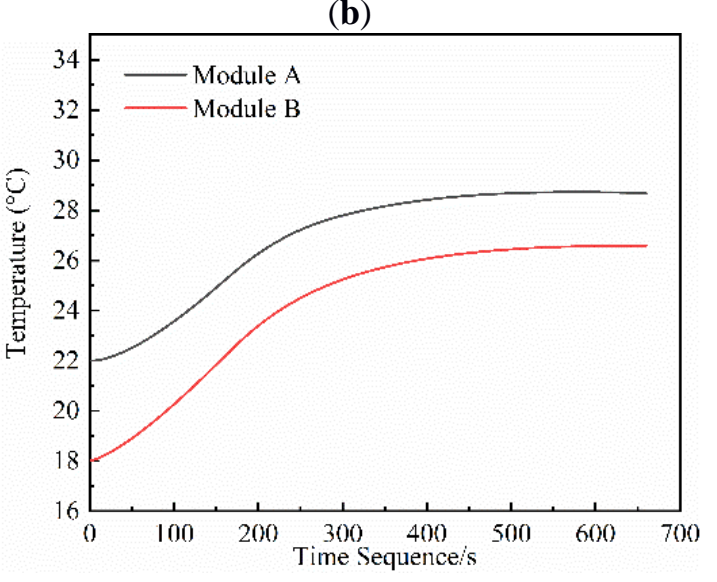

(d)

Figure 6. Simulation results of 200 A discharge: (a) temperature distribution of module A; (b) temperature distribution of module $\mathrm{B} ;(\mathbf{c})$ temperature gradient of module $\mathrm{A} ;(\mathbf{d})$ average temperature of module $\mathrm{A}$ and $\mathrm{B}$ from the side view.

In Figure 6, the distribution in the modules is similar, and the temperature rise difference is related with the internal resistance. The batteries are the heat source; thus, the temperature around the inner batteries is the highest. The heat dissipated to the foams and the frameworks slowly with the time going. Additionally, because of the low thermal conductivity of the foams and frameworks, the temperature drops slowly as well. The temperature in Figure 6 is calculated by the average temperature of the frameworks, which is in accordance with the experiment. Additionally, the final error between the simulation and experiment is within $1{ }^{\circ} \mathrm{C}$. The simulation results are reliable under all the discharge rates set.

Figure 7 shows the results of equivalent internal resistance and comparison of temperature rise between the experiment and simulation under different discharge rates. The equivalent internal resistance decreases with the discharge rates, while the temperature rise increases. The maximum temperature difference is smaller than $2{ }^{\circ} \mathrm{C}$, which testifies that the heat generation can be estimated accurately by the equivalent internal resistance calculation.

The batteries are the main object in the battery module, and their discharge characteristics and aging characteristics are easily affected by the temperature; therefore, the temperature distribution in the batteries zone is focused. Figure 8 shows the temperature rise and temperature difference of the battery zone. The highest temperature rise and temperature difference appear at $20 \mathrm{C}$, and they are 23.1 and $5.2^{\circ} \mathrm{C}$, respectively. The values are within the accepted range until 50\% DOD; however, when the discharge continues to 
$0 \% \mathrm{DOD}$, the temperature rise and the temperature difference will continue to increase. Additionally, then, an appropriate thermal management method that can decrease both the temperature rise and temperature difference should be proposed. In addition, compared with Figure 7, the highest temperature difference in the whole battery module appears between the batteries and the frameworks, which is about $17.7^{\circ} \mathrm{C}$; this means that when the temperature difference is measured by the experiment, the location of the thermocouples is important, or it will mislead the thermal management design.

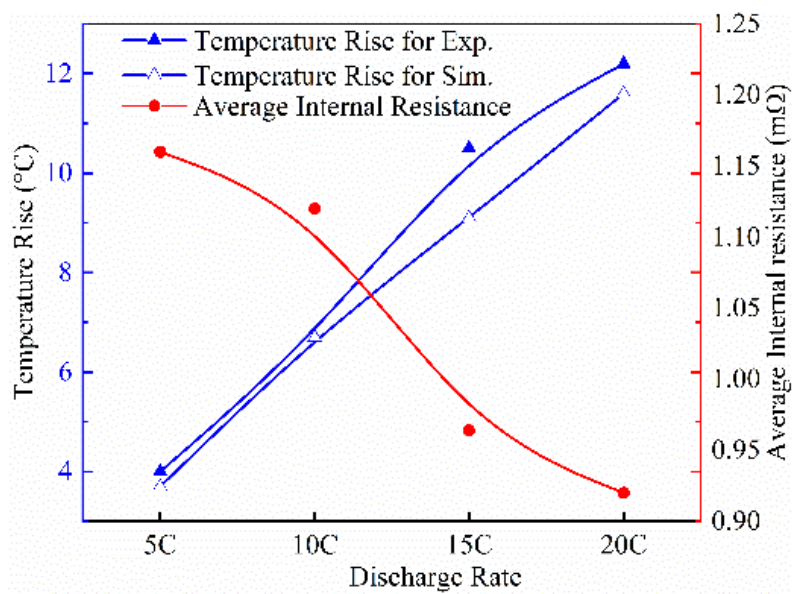

Figure 7. The results of equivalent internal resistance and comparison of temperature rise between the experiment and simulation under different discharge rates.

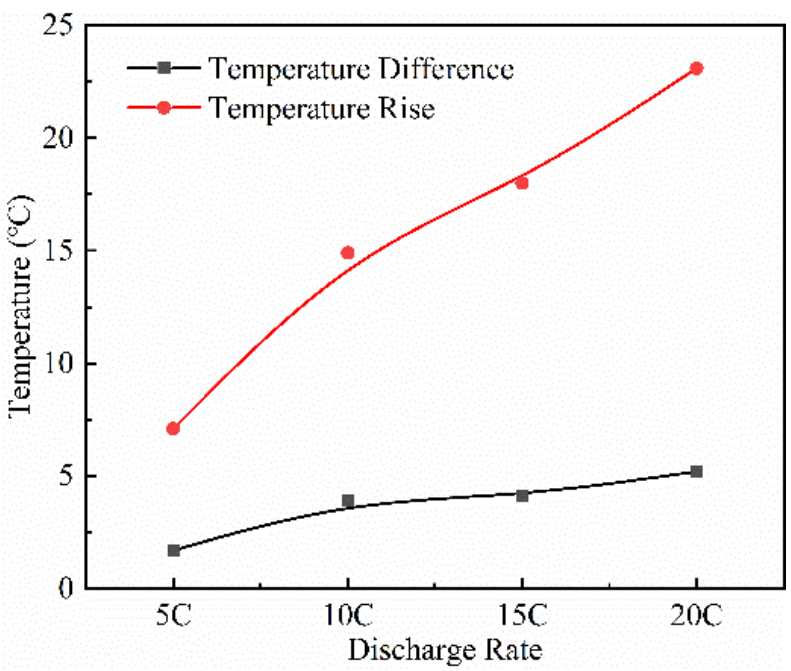

Figure 8. The temperature rise and temperature difference of the batteries.

\section{Conclusions and Outlook}

This paper studies the thermal performance of lithium titanate oxide anode based battery modules under high discharge rates by both experiment and simulation. It is found that the thermal performance can be estimated accurately with a fast heat estimation method, which uses the hybrid pulse power characteristic of different timescales to measure the equivalent internal resistance. With the increase of the discharge rates, the chosen timescale of the calculation is smaller, and the equivalent internal resistance is smaller, while the temperature rise is higher. Finally, the thermal characteristics in the batteries zone are investigated. It is found that the highest temperature rise and temperature difference appears at $20^{\circ} \mathrm{C}$, and they are 23.1 and $5.2{ }^{\circ} \mathrm{C}$, respectively. When discharge continues, the temperature rise and temperature difference will continue to increase. 
The battery modules need to be managed under higher discharges; an appropriate thermal management method that can decrease both the temperature rise and temperature difference should be proposed. Furthermore, the thermal management system should respond quickly under higher discharge rates.

Author Contributions: Conceptualization, Z.L. and Y.G.; methodology, H.C. and C.W.; supervision, Y.S. and P.Y. All authors have read and agreed to the published version of the manuscript.

Funding: This research received no external funding.

Conflicts of Interest: The authors declare no conflict of interest.

\section{References}

1. Mauger, A.; Armand, M.; Julien, C.M. Challenges and issues facing lithium metal for solid-state rechargeable batteries. J. Power Sources 2017, 353, 333-342. [CrossRef]

2. Chacko, S.; Chung, Y.M. Thermal modeling of Li-ion polymer battery for electric vehicle drive cycles. J. Power Sources 2012, 213, 296-303. [CrossRef]

3. Shah, K.; Vishwakarma, V.; Jain, A. Measurement of multiscale thermal transport phenomena in li-ion cells: A review. J. Electrochem. Energy Convers. Storage 2016, 13, 030801. [CrossRef]

4. Yang, A.; Wang, Y.; Yang, F.F. A comprehensive investigation of lithium-ion battery degradation performance at different discharge rates. J. Power Sources 2019, 443, 227108. [CrossRef]

5. Feng, X.N.; He, X.M.; Ouyang, M.G. A coupled electrochemical-thermal failure model for predicting the thermal runaway behavior of lithium-ion batteries. J. Electrochem. Soc. 2018, 165, A3748-A3765. [CrossRef]

6. Qi, W.B.; Ben, L.B.; Yu, H.L. Improving the electrochemical cycling performance of anode materials via facile in situ surface deposition of a solid electrolyte layer. J. Power Sources 2019, 424, 150-157. [CrossRef]

7. Wu, W.X.; Wang, S.F.; Wu, W. A critical review of battery thermal performance and liquid based battery thermal management. Energy Convers. Manag. 2019, 182, 262-281. [CrossRef]

8. Florian, H.; Jonas, T.; Sabine, W. Experimental investigation of the thermal and cycling behavior of a lithium titanate-based lithium-ion pouch cell. J. Energy Storage 2018, 17, 109-117.

9. Wu, B.; Yufit, V.; Marinescu, M. Coupled thermal-electrochemical modelling of uneven heat generation in lithium-ion battery packs. J. Power Sources 2013, 243, 544-554. [CrossRef]

10. Rumpf, K.; Naumann, M.; Jossen, A. Experimental investigation of parametric cell-to-cell variation and correlation based on 1100 commercial lithium-ion cells. J. Energy Storage 2017, 14, 224-243. [CrossRef]

11. Peng, X.; Ma, C.; Garg, A. Thermal performance investigation of an air-cooled lithium-ion battery pack considering the inconsistency of battery cells. Appl. Therm. Eng. 2019, 153, 596-603. [CrossRef]

12. Smith, K.; Wang, C.Y. Power and thermal characterization of a lithium-ion battery pack for hybrid-electric vehi-cles. J. Power Sources 2006, 160, 662-673. [CrossRef]

13. Xun, J.Z.; Liu, R.; Jiao, K. Numerical and analytical modeling of lithium ion battery thermal behaviors with different cooling designs. J. Power Sources 2013, 233, 47-61. [CrossRef]

14. Voicu, I.; Rizk, R.; Louahlia, H. Experimental and numerical study of supercapacitors module with air cooling. Appl. Therm. Eng. 2019, 159, 113903. [CrossRef]

15. Chen, K.; Wu, W.D.; Yuan, F. Cooling efficiency improvement of air-cooled battery thermal management system through designing the flow pattern. Appl. Therm. Eng. 2019, 167, 781-790. [CrossRef]

16. Chen, J.Y.; Yu, L.Y.; Wang, G.Z. Analysis of optimization of wind cooling system in power battery. Chin. J. Power Sources 2019, 043, 84-87.

17. Hosseinzadeh, E.; Marco, J.; Jennings, P. Combined electrical and electrochemical-thermal model of parallel connected large format pouch cells. J. Energy Storage 2019, 22, 194-207. [CrossRef]

18. Liu, H.W.; Li, J.J.; Xie, X.Y. Application of accelerating rate calorimeter in the lithium-ion battery thermal test. J. Integr. Technol. 2015, 1, 51-59.

19. Philipp, S.; Ehsan, K.; Thomas, N. Adaptive modeling in the frequency and time domain of high-power lithium titanate oxide cells in battery management systems. J. Energy Storage 2020, 32, 101966.

20. Anup, B.; Kotub, U.W.; Widanage, D. A study of the influence of measurement timescale on internal resistance characterisation methodologies for lithium-ion cells. Sci. Rep. 2018, 8, 21.

21. Krishnan, S.; Hariharan, V.; Senthil, K. A nonlinear equivalent circuit model for lithium ion cells. J. Power Sources 2013, 222, 210-217.

22. Yoana, F.P.; Cecilio, B.; David, A. Determination of suitable parameters for battery analysis by Electrochemical Impedance Spectroscopy. Measurement 2017, 106, 1-11.

23. Yasir, M.G.; Li, H.; Zheng, J.P. Applicationn of physical electric circuit modeling to characterize Li-ion battery electrochemical processes. J. Power Sources 2014, 270, 113-120. 
24. Yasir, A.; Tomi, L.; Juha, K. Heat generation in high power prismatic Li-ion battery cell with $\mathrm{LiMnNiCoO}_{2}$ cathode material. Int. J. Energy Res. 2014, 38, 1424-1437.

25. Liu, Z.H.; Wang, C.; Guo, X.M. Thermal characteristics of ultra-high power density lithium-ion battery. J. Power Sources 2021, 506, 230205. [CrossRef] 